\title{
Analyzing Discourse Coherence in Bengali Elementary Choras (Children's Nursery Rhymes)
}

\author{
Rajoshree Chatterjee $^{1} \&$ Jayshree Chakraborty ${ }^{2}$
}

${ }^{1}$ Indian Institute of Technology Kharagpur, Department of Humanities and Social Sciences, Indian Institute of Technology Kharagpur. Kharagpur - 721302. West Midnapore, West Bengal. ORCID ID: oooo-ooo1-5145-1889.

Email id: rajoshri.chatterji@gmail.com

${ }^{2}$ Indian Institute of Technology Kharagpur, Department of Humanities and Social Sciences, Indian Institute of Technology Kharagpur. Kharagpur - 721302. West Midnapore, West Bengal. ndian Institute of Technology Kharagpur. ORCID ID: oooo-0oo2-7926-2956. Email id:shree@hss.iitkgp.ernet.in

\begin{abstract}
The present paper aims to explain the process of meaning making in Bengali elementary Choras (children's nursery rhymes) by their intended target audience, little children, who are yet to develop their semantic, cognitive or linguistic skills. Chora, the Bengali oral folkloric counterpart of nonsensical verses for children, can be characterised as a type of dynamic discourse where socio-cultural elements occur abundantly though asymmetrically. Outlined by intermittent cohesive gaps, such discourses are however found to be thoroughly enjoyed and appreciated by the little children, despite their lack of prior textual and/or contextual awareness. Following this, it is observed that such rhymes or Choras are more about experiencing amusement that the children derive from the verses rather than understanding their denotative or connotative sense. Meaning making of such rhymes by the little children, we claim, occur not through the processing of semantics of the text but by directly experiencing the communicative intent of the discourse. Coherence of such dynamic and discontinuous discourses is therefore attained when their pragmatic intent, that is enjoyment - intertwined in the verses, is identified by the little children and reciprocated through affirmation. The analysis detects the predominance of coherence constructed at the discourse level and accordingly the methodology adopted to explain cognizance in elementary Choras is the theory of Discourse Coherence (Wang and Guo, 2014) which claims that coherence in discourse can be achieved jointly by the discourse producer as well as the receiver.
\end{abstract}

Keywords: Choras, Cohesion, Discourse Coherence, Pragmatic Intent

\section{Introduction}

Meaning making or comprehensibility is an important feature of a text's acceptability, influence and prominence. A text is adequately intelligible because of unity both at the textual level, visible through the in-text cohesive links, and at the contextual level, where the target audiences' prior schemata helps to connote meaning. Choras, in general and

(c) AesthetixMS 2019. This Open Access article is published under a Creative Commons Attribution Non-Commercial 4.0 International License (http://creativecommons.org/licenses/by-nc/4.o/), which permits non-commercial re-use, distribution, and reproduction in any medium, provided the original work is properly cited. For citation use the DOI. For commercial re-use, please contact editor@rupkatha.com. 
elementary Choras in particular, are however abundant in textual cohesive gaps; moreover, the target audience lacks the necessary awareness to process the semantic content of such texts. Despite this, the fact that elementary Choras are enjoyed by the children to the fullest poses a challenge to the possibility of meaning making. The objective of the study, therefore, is to explain how comprehension witnessed in the form of enjoyment and amusement in little children with limited cognitive skills, takes place in Bengali elementary Choras. In order to have a comprehensive understanding of the proposed study it becomes imperative to explain the two terms related to unity of a text: Cohesion and Coherence which helps to analyse the process of intelligence and meaning making in discourse.

1.1 Cohesion and Coherence are related to each other as both the concepts come under the umbrella term for meaning making in effectively organized and meaningful discourses - both spoken and written. While cohesion is the operational continuity in a text, coherence contributes to logic and rationality of the entire discourse when situated in its context. The concepts necessarily revolve around relatedness and are the fundamental properties responsible for uniting ideas rationally, logically and linguistically. They are two similar looking yet difficulty distinguished styles in the field of discourse analysis and their interrelation depends much on the nature of the text. Cohesion and coherence are the prime factors behind converting a random set of utterances to a proper comprehensible discourse, and without their functioning, either together or individually, the intelligibility of a discourse may totally collapse.

\subsection{What is Cohesion}

Linguists Michael Halliday and Ruqaiya Hasan, in their pioneering work Cohesion in English, (1976) introduced the concept of Cohesion. According to them, 'the concept of cohesion is a semantic one; it refers to relations of meaning that exist within the text and that define it as a text'. Cohesion is thus an interlinking semantic property of a discourse. Halliday and Hasan, described this text connectedness in terms of Grammatical Cohesion

- which is based on structural content, and Lexical Cohesion, which is based on lexical content and background knowledge of the text.

\subsection{What is Coherence?}

Van Dijk, in his book 'Text and Context' defines Coherence as the "semantic property of discourse, based on the interpretation of each individual sentence relative to the interpretation of other sentences." (Van Dijk, 1977, p.96). It is the agreement of text with its context, which is there in the mind of the reader who tries to make sense of the text and its constituents, by situating the former in its social context. Coherence is therefore subjective, and it is not texts that cohere but it is the readers who make texts coherent. Coherence also includes the cognitive ability of the reader to make a text intelligible by 'interactively negotiating with a given socio-cultural setting' and therefore making it less 
dependent on the 'language of discourse or the text itself' (Gernsbacher and Givon, 1995) and it is due to this that coherence may not always be determined by the working of grammar and semantics operating within the text. Coherence also leaves the interpretation of the discourse free, open and at the discretion of the reader, by majorly taking into account factors beyond the text. By emphasizing on prior background awareness and ability of the reader, other available visual, verbal and nonverbal cues, socio contextual information, coherence takes away the sole monotony of meaning making from textual cohesion.

\subsection{Working of Cohesion and Coherence}

Although it is true that textual cohesion is necessary for coherence of the entire discourse, many linguists have pointed out that textual cohesive markers alone do not determine a coherent discourse. There may be many visible cohesive markers yet no proper coherence or even a single sentence can stand united logically without any cohesive ties in the text. Following this, a majority of linguists have prominently proposed a two way approach to make a discourse meaningful:

i. (Textual) Cohesion leading to Coherence of the discourse: Wang and Guo (2014) classify Cohesion and Coherence according to different distinctive studies by various scholars. According to them, Linguists like Halliday and Hasan (1976) and Van Dijk (1977) take up a pure linguistic perspective to study the two ideas and suggest cohesion as the necessary condition for coherence. According to them, Cohesion is an interlinking textual property and its importance lies in the continuity it expresses between segments of a text, making it a semantic edifice. According to Hasan and Halliday (1976), it is this cohesion which provides texture to a text, which helps to differentiate it from a non-text. They opine that textual cohesion in a discourse is primary because it is cohesion that establishes and determines the structural unity in a text. In similar lines, Hoey (1991), opines that text organization can be achieved with the help of lexical features and syntactic repetition which construct a bonding between the sentences in a text which serve as a major cohesive tie. Such claims, however, seemed to be too strong and have been challenged by other researchers. According to them, the textual cohesive ties identified by Halliday and Hasan, are not the only source of texture of the text. A text may have multiple factors beyond the words that bring about meaning and cognizance.

ii. Coherence (of the discourse) leading to textual cohesion: In contrary to the previous ideas, linguists like Widdowson and Crystal have taken a different approach and they also acknowledge the importance of pragmatic knowledge in the interpretation of coherence. According to them, Coherence is the semantic relatedness brought about by the connectivity that a discourse establishes with its context. Widdowson (1978) recognizes the importance of context in understanding the structure of a discourse and says that a text can be coherent without "overt linguistically signaled" cohesion. According to Crystal (1985), coherence involves the study of factors such as the language users' knowledge of the world, the inferences they make, the assumptions they hold and 
also involves the study of the way in which communication is mediated through the use of speech acts. Reinhart (1980) in similar lines does not separate cohesion from coherence, but merge the two by saying coherence as 'the semantic and grammatical connectedness between discourse and context'. Blakemore $(1987,1992)$ emphasizes on the importance of the linguistic form of the text, its context and relevance of the speakers' assumption. He also says that interpretation of a discourse is not always based on the propositions explained but rather on "nonlinguistic and contextual features" accompanying the discourse. The other set of linguists, like Grabe (1985), Blakemore $(1987,1992)$ and Schiffrin (1987) further diversify the study and explain coherence on the lines of mental phenomenon, overall theme, cognitive knowledge and psychological perspective. According to Schiffrin, cohesion is achieved by 'interaction of speaker and the hearer' and coherence is dependent on 'successful integration of verbal and nonverbal devices to situate a message and the readers' ability to interpret'.

\subsection{Discourse: Product and/or Process?}

The importance of textual cohesion and whether cohesion leads to coherence, or vice versa, or they work in a circular manner in a text, depends extensively on whether the discourse under consideration is defined as a 'Product' or a 'Process'. According to Wang and Guo (2014), a discourse is taken as a 'product' if coherence relations are realized on the surface of the discourse through the linguistic ties connecting various parts of the text. Here cohesion operating inside the text is in accordance with coherence of the discourse. These types of discourses are particularly meant for audiences with prior familiarity of the discourse structure. Even before the reader starts participating in the discourse, he/she already has formed a perception and expectation about the same. For example, when an adult takes up a crime fiction novel, just by the book cover visuals, the name of the book, the author or the awareness of the genre, the reader has already built up a frame of mind, and has probably tuned his/her understanding and expectations from the content of the book, which plays an important part in forming a coherent discourse. On the contrary, collecting from the ideas of Wang and Guo (2014), when discourse is considered as a dynamic 'process', coherence is constructed through interaction in the actual context. It takes into account the pragmatic, cognitive and psychological aspects encompassing non-linguistic factors such as inference, interaction and socio-cultural context. In such discourses, meaning making of the ongoing discourse on part of the audience is made through the latter's direct participation in the simultaneous interactions. Here the participants are not witnessing the context from outside as they do in discourses considered as a 'product', but because of their limited prior familiarity with the discourse, they construct meaning by actively participating and situating themselves in the same.

\subsection{The dataset (Choras) - an example of Discourse as a Process and/or Product?}

From the foregoing review of cohesion and coherence, it becomes clear that the nature of a text depends much on the nature of the discourse it is a part of, and the essence and 
characteristics of Bengali Children's Rhymes, is such that it can be claimed as examples of both 'discourse as a static product' and/or 'discourse as a dynamic process'. The elementary group of Choras, however, can strictly be taken as examples of 'discourse as a process'. This particular observation along with some other related assumptions, serves as a significant base to our analysis. These assumptions are enumerated as follows:

- Elementary Choras serve as a medium for their target audience to make their first interaction with their immediate surroundings or the outside world.

- This suggests that such Choras are immensely interactive in nature and such discourses are dynamic and not fixed or static.

- The target audience do not have any prior linguistic, semantic or cognitive skills.

- The effect of these interactive verses is seen in the children in the form of derived positivity, enjoyment and amusement making the semantic content of the Choras immaterial.

Thus we assume that for children of the target group, perception of the elementary category of Choras, does not occur by processing meaning as a given end-product. The Choras instead are experienced directly by the participants' direct involvement and engagement with the immediate context, generating and constructing understanding through a constant and dynamic process.

\subsection{Methodology}

The above mentioned observations necessitate top down approach (as opposed to bottom up approach of discourse analysis) i.e the discourse coherence approach as the best measure to analyze meaning making in elementary Choras. Discourse coherence, focuses on achieving comprehensive coherence and has been defined as 'the semantic relationship between propositions or communicative events in discourse, which is a feature of the perception of the discourse rather than the discourse itself. This majorly incorporates semantic as well as pragmatic functional relations. The elementary Choras under discussion, serve as dominant examples of interactive discourses meant for children with extremely limited cognitive skills, are realized through their audiences' direct involvement in the discourse more than their grammaticality and connectedness. The audience, obliging to their capacity, are not capable of grasping any semantic continuity however, they do recognize the pragmatic intent of the discourse and the communicative intent of the producer through the characteristical attributes of pure recreation and enjoyment provided by the genre.

\section{Analysis}

\subsection{What are elementary Choras?}

The dataset of the present study, Bengali elementary Choras (tfora:), fall under the broad domain of children's rhymes, the major elements of which are emotions ranging 
from affection and wheedle to humor, enjoyment and to the sense of awareness and cultural inclusion. These uncomplicatedly composed, short, simplified and apparently meaningless verses often seem to be manifestations of the characteristics of childdirected speech and revolve around common themes from our surroundings. The date of composition of the elementary Choras under consideration is yet to be ascertained as they have been primarily a part of the oral literature. They were possibly orchestrated during the late nineteenth or early twentieth century when the scenario of the Bengali cultural household was much different from that of the present day. The Choras usually narrated a depiction of the setting of the rural Bengali household, its people, traditions and ways of everyday life, such that it was easy for the (contemporary) children with their limited life experiences, to comprehend and identify with the same. Choras - as an integral part of the Bengali oral folkloric tradition, have been carried forward through generations, however, they may not be as relevant and suited to the audience of the present day who can connect to the world in a click. The rhymes composed in recent times greatly differ from their ancestral counterparts in terms of their thematic encompassment which necessarily reflects the contemporary setting. However, to a Bengali native speaker even of the present time, Choras are essentially accepted as the age-old, recited, remembered and retained rhythmic verses (as exemplified) and the not rhymes found in the present digital world. Choras are thus a treasured and timeless possession of the Bengali children's literature inventory which has taught millions of children the ways of the world by directly experiencing the context through natural (or artificial) means.

\subsection{How are elementary Choras unique?}

Elementary Choras differ considerably from Choras meant for slightly advanced children in terms of textual cohesive properties, semantics and thematic continuity. The themes or the subject matter of such Choras fluctuate from colorful and loud to weird and unnatural. They give us vibrant images of the actual world to funny unnatural incidents that are probably not even possible in real life situations, all united by pleasure and positivity at the receivers' end. A dominant feature of the elementary Choras defining their uniqueness is their textual cohesive gaps. These gaps may be in the form of unrelated and disjointed ideas, non-words and/or nonsensical phrases, lexical cohesive gaps surfacing through personification of animate or inanimate objects, actions deviant from the normal or accepted course of events and semantically unrelated words grouped together based on their similar rhyme scheme. It should be also be largely noted here, that whatsoever the literal or figurative or cultural connotations the Choras might incorporate, the primary purpose of these is to disseminate pleasure, relaxation and recreation in their reader. This is chiefly because the target audience of the elementary Choras are little children with very limited cognitive, semantic and linguistic skills, who are not capable of understanding the verses, yet can experience the enjoyment, positivity and warmth given out by the verses. 


\subsection{Discourse Coherence in elementary Choras}

Wang and Guo (2014) relates to unity at the discourse level, also known as Discourse Coherence, in terms of semantic and/or pragmatic functional relations. The semantic functional relation encompasses various types of functional relations between the events like 'cause and effect', 'parallel description' etc. The pragmatic functional relation mainly identifies the pragmatic intent of the discourse/speaker. In the case of elementary Choras, it can be said that the target audience can discern and perceive the pragmatic intent of the verses, though their cognitive ability limits them from recognizing any semantic functional relation between the utterances. In elementary Choras therefore, the underlying uniting and binding force is the enjoyment operating throughout the verses. Coherence of the discourse is thus achieved when the pragmatic intent of Choras, that is enjoyment, intertwined in the verses, is identified and reciprocated through affirmation by the target audience, that will be discussed in detail in the later portion of the study.

\subsection{Data}

\begin{tabular}{|l|l|l|}
\hline 1. & $\begin{array}{l}\text { Dol Dol duluni, } \\
\text { Ranga mathay chiruni } \\
\text { বড় }\end{array}$ & $\begin{array}{l}\text { Swing Swing Swinging } \\
\text { Comb on a red head } \\
\text { Niye jabe tokhon-i } \\
\text { The groom will come just now } \\
\text { And take away (the bride) just } \\
\text { then }\end{array}$ \\
\hline 2. & $\begin{array}{l}\text { Aata gaache tota pakhi } \\
\text { Daalim gaache mou, } \\
\text { Ato daaki tobu kotha } \\
\text { Kouna kano bou? }\end{array}$ & $\begin{array}{l}\text { The parrot is on the custard- } \\
\text { apple tree } \\
\text { The bee on the pomegranate } \\
\text { tree, } \\
\text { I call thee for so long } \\
\text { But why don't you speak bou? }\end{array}$ \\
\hline
\end{tabular}


8 | Rupkatha Journal, Vol. 11, No. 3, 2019

\begin{tabular}{|c|c|c|}
\hline 3.বক বকম & $\begin{array}{l}\text { Bok-bokom payra } \\
\text { Mathay diye tayra } \\
\text { Bou shajbe kal ki? } \\
\text { Chorbe shonar palki }\end{array}$ & $\begin{array}{l}\text { Bok Bokom Pigeons } \\
\text { Wearing a tiara on the head } \\
\text { Will you dress up as a bride } \\
\text { And ride a golden palanquin? }\end{array}$ \\
\hline $\begin{array}{l}4 . \\
\text { কদন }\end{array}$ & $\begin{array}{l}\text { Chaand utheche, } \\
\text { Phool futeche } \\
\text { Kodom tolay ke? } \\
\text { Haathi naachche, Ghora } \\
\text { naachche, } \\
\text { Shonamonir bey }\end{array}$ & $\begin{array}{l}\text { The Moon has risen, } \\
\text { The flowers have blossomed, } \\
\text { Who is the one sitting under a } \\
\text { kadam tree? } \\
\text { Elephants are dancing, horses } \\
\text { are dancing } \\
\text { It's my darling's (daughter's) } \\
\text { wedding }\end{array}$ \\
\hline 5. & $\begin{array}{l}\text { Hattimatimtim, } \\
\text { Tara maathe pare deem, } \\
\text { Tader khara duto shing, } \\
\text { Tara hattimatimtim }\end{array}$ & $\begin{array}{l}\text { Haat-tim-a-tim-tim, } \\
\text { They lay eggs in the field, } \\
\text { They have two straight horns, } \\
\text { They are the Haat-tim-a-tim- } \\
\text { tim. }\end{array}$ \\
\hline
\end{tabular}

\subsection{Analyses of the Choras}

It is true that elementary Choras, as exemplified above, display prominent cohesive gaps and discontinuities surfacing at every level as a part of their characteristics. However, what is more important is that the very young audience derive enjoyment from them not because they understand these gaps but because they understand the intent of these verses, which is to disseminate enjoyment and amusement in the receiver. In the following section, the various sources of amusement in the Choras have been discussed.

Chora 1: In the first Chora, the first two lines 'Dol dol duluni' and 'Ranga mathay chiruni' portray two simultaneous events, which are common and relatable instances of everyday life. The little audience who come across the two unrelated lines meaning 'a 
child is playing on a swing' and 'a comb on a (red) head' along with the appropriate visuals depicting the same, may not be able to decipher the semantics or exact purpose of the words, but they are a witness to such experiences in their immediate, everyday surroundings and are therefore able to relate to them because of their occurrence in the same environment. The next two lines 'Bor asbe ekhuni' and 'Niye Jabe tokhuni', portray one event as the result of another event, where 'a groom coming' mandatorily results in 'taking away (the bride)'. The major sources of drawing enjoyment in the Chora are its rhyming words and rhythmic pattern, which irrespective of any other factor, unites the verses through phonological parallelism, helping the reader or listener unconsciously retain the verses for a long time while simultaneously deriving amusement The words are simple, uncomplicated and usually relate to objects and entities and as a part of motherese (ranga, duluni) they are uttered carefully with extended intonation which amuse the children. The Chora is thus comprehended by experiencing comprehensive enjoyment through a blend of associations, interactions and of course music.

Chora 2: The first two lines of the second Chora describe the birds sitting in fruit trees which are everyday occurrences around a (rural) household. The listener enjoys the rhyming of the words aata-tota, bou-mou and through the visuals and/or real life demonstrations from the reciters, learns to identify and associate with the various objects and entities of the nature and its immediate environment. The natural environment encircling birds, insects, trees etc. portrayed in the Choras, becomes a part of the child's knowledge inventory. The next two lines however drastically jump to change the thematic parallels of the natural environment to talk about a shy bride who does not respond or talk even after repeatedly calling her. Though a child of such tiny age cannot really decipher the meaning of marriage or a "shy bride", children are often found to be introduced to such ideas by the reciter or the caretaker, at times by just repetition. The major uniting factor of unrelated verses is the same rhyme scheme, pleasure and enjoyment drawn from the associations that children of the target age group can associate and identify with, thus creating coherence.

Chora 3: The first and the second lines of the Chora "Bok Bokom Payra" and "Mathay diye tayra" are two unrelated utterances occurring simultaneously. It must be noted here that 'Bok-Bokom' is an onomatopoeic word used to describe the sound made by pigeons. The first line has a pedagogic purpose of teaching the little audience identification and recognition of natural entities present in everyday surroundings by making the best use of the onomatopoeic system. The children are now becoming aware of animal and bird sounds and can associate one to another, which, with time is being stored as its schemata. One of the best examples of the instructive effects of such interactions, which perhaps we have often noticed, is a child uttering "bow-wow" on noticing a real life dog. This is because of the identification and association of the onomatopoeic sounds with their corresponding entities that the child has picked up from interactions in the everyday natural environment. Lines 2, 3 and 4 abruptly shift the focus from the pigeon to a girl decking up as a bride by wearing a tiara sitting in a palanquin, is solely united by the rhyme scheme. The child is made versant with all such prevalent socio cultural customs, practices and rituals which with repeated and direct exposure 
become a part of its knowledge inventory. It may however be noted that since the cognitive capacity of the target audience limits the comprehension of all such social connotations, such expressions are necessarily wrapped up in patterning rhyme scheme providing them enjoyment. The pleasure derived further leads the child to familiarize and associate with the context and identify with the envisage imaged by the Choras, thus forming coherence.

Chora 4: In the next Chora, the first line has two parts "Chaand utheche", "Phool phuteche" which being parallels in nature, sketch cheerful, merry and positive occurrences of the everyday neighborhood. Lines 2, 3 and 4, much like the previous Choras depict a change of events integrated just by the rhyme scheme. Such are the cohesive discontinuities of this particular genre. The second line, revolves around the idea of marriage like most other Choras discussed above, and introduces the idea of a "kodom - tola" (meaning - underneath a kodom, a particular flower breed, tree) which is a homey surrounding ideally meant for marriage setups. The last two lines which talk about animals dancing in the kodom tola (which traces back to the mythological love story of Radha Krishna) for the wedding of an adored girl, paint the idea marriage as a joyous as well as romantic social ritual. The Children experiencing the Choras, are therefore being introduced to different entities and rituals of the natural and cultural environment which they automatically learn to identify, associate and acclimatize with. The entire Chora, through its different unrelated words like "Chaand utheche, phool phuteche", "haathi naachhe, ghora naachcche" conjoined by the rhyme scheme primarily attempt to portray a merry and jubilant occasion and experience it together as one united source of amusement thus ruling out the cohesive gaps of the Chora.

Chora 5: In the fifth Chora, the very word 'Hattimatimtim' is a nonsense word. It is an imaginary word announcing an unreal animal christened by this 'absurdly-hilarious name' - composed of a cluster of rhythmic sounds. The Chora elucidates the various characteristics and functions of this entity called 'hattimatimtim'. The lines occur parallelly while perfectly fitting in the rhyme scheme, portraying the imaginary animal which shares similar features with a real animal, probably a duck or a hen often found in local environs. The main purpose of the imaginary word which makes meaning only in the context of its occurrence, and not in isolation, is to maintain music and rhythm of the Chora while opening up ample avenues for amusement along with pedagogic absorption and future retainment. The music and the illustrations which can be directly experienced by the target audience, help them visualize/recollect and form associations with some similar entity and its activities, thus forming coherence.

In most of the Choras, themes related to social customs, rituals and traditions are observed to dominate. Being regularly and repeatedly exposed to such articulations, children may learn to imbibe such associations and correlations between different sociocultural events. The words, with the help of visuals and aided by real life experiences from the surroundings help the child from its babyhood to diagnose diversified social realities, practices and observances, which in turn help them to build their world knowledge. The social ceremonies, particularly (child) marriages find an important recognition in the Choras, which with its regular and repeated reference become a familiar phenomenon for 
children to adapt with just like any other socio-cultural reality. Marriage, as a recurrent theme of elementary Choras, portraying little girls as well as boys getting married, is perhaps because of the-then prevalent social practice when child marriages were a regular routine. It was then seen as a decisive social reality and latently acquainted the children, especially girls, with the idea of looking beautiful, decking up as a bride, leaving their maiden home post marriage and the (expected) socio-cultural norms and stereotypes of a girl (bride) being silent, shy and submissive. Choras, thus, are one of the major tools used to normalize the socio-cultural scenario of the contemporary society. Therefore the thematic content of the Choras is perhaps because of their time of composition, when these occurrences were a part of the everyday social reality. They however do not come under the purview of the present study because of its focus on the nature of learning rather than the content of learning. Despite the fact that the audience after years of native exposure might incorporate such events in their world knowledge inventory, at the existing stage of maturity they are capable of meaning making only through extra textual factors free of semantic connotation.

\subsection{Findings}

Choras, as a spoken genre, are not part of any planned discourse which might require proper textual and contextual cohesive ties. They are spontaneous, unplanned interactions whose main purpose is the production of enjoyment. In such interactive and reciprocative texts, to complement the cognitive capacity of the target audience, the discourse is not made up of just the words alone. The entire immediate cultural environment and familiar surroundings, the non-verbal actions, events and gestures form a part of the discourse, which help to make sense and cognizance to the target audience. The major responsibility of the interactive exchange falls on the speaker (usually the mother or caretaker of the child, reciting the rhymes to them) who is aware of the purpose of such discourses and takes care to induce response in the reader. To meet the purpose of the Choras or in other words, make meaning of the Choras to the little children with limited cognitive capacities, the speaker/reciter uses the rhythm and rhyme scheme, props and relevant associations from the surrounding habitat, varied communicative expressions and also performs primary speech acts accordingly to lure the receivers. The little children who have zero cognitive, linguistic or semantic skills are not only listening to the Choras, but simultaneously experiencing and participating in different undocumented happenings of the surroundings, thus making all the unrelated events, activities and utterances form a part of the same cohesive discourse. The toddlers can now enjoy the positivity and the effect that they have directly perceived through the tone, touch, gestures, non-verbal communications, warm physical vibrations and associations to achieve the desired purpose of amusement, enjoyment and positivity along with simultaneously building up their world knowledge inventory.

\subsection{Conclusion}

In elementary Choras, meaning making by the young target audience is possible by their direct participation in the interactive exchange and recreating enjoyment from it. The adoption of the discourse coherence approach is justified in the present context of 
elementary Choras because it includes the pragmatic functional intent, serving as an adhesive in these apparently inconsistent verses. This can be witnessed through the different extra textual features identified in the Choras - visuals, non-verbal elements along with the major rhyme scheme, mesh with each other, bestowing the children with associations that they can easily identify with, thereby promoting strong emotional bonding with the environment. Thus in elementary Choras, conception of coherence is a constant and concurrent process through the participants' active socio-cultural and contextual interaction and reciprocation. The sheer in-cohesion dominating at every level in these texts does not lead to incoherence of the text, instead, the coherence achieved at the discourse level flattens all the discontinuities in the verses. Meaning making in elementary Choras which is a continual and uninterrupted process witnessed through the joyous responses in the little children, therefore takes discourse coherence as the starting point of overall unity, making the apparently "in-cohesive" Choras perfectly coherent.

Note: All the translations and transliterations used in the paper are done by the authors unless otherwise mentioned.

\section{References}

Bublitz, W. (2011). Cohesion and Coherence. In J. Zienkowski, J. Östman \& J. Verschueren, Discursive Pragmatics. John Benjamins Publishing Company.

Cain, K. (2003). Text comprehension and its relation to coherence and cohesion in children's fictional narratives. British Journal Of Developmental Psychology, 21(3), 335-351. doi: 10.1348/026151003322277739

Carrell, P. (1982). Cohesion Is Not Coherence. TESOL Quarterly, 16(4), 479. doi: 10.2307/3586466

Fitzgerald, J., \& Spiegel, D. (1986). Textual Cohesion and Coherence in Children's Writing. Research In The Teaching Of English, 20(3), 263- 268.

Ghani, A. Coherence and Schematic Correlation in William Blake and Gerald M. Hopkin's selected poems (MA). College of Languages.

Gonzalez, A. L. (2016). Music and Language Development: Traits of Nursery Rhymes and Their Impact on Children's Language Development. Diss. California Polytechnic State University.

Halliday, M., \& Hasan, R. (1985). Cohesion in English. Longman.

Hellalet, N. (2013). Textual coherence in EFL Student Writing. IOSR Journal Of Humanities And Social Science, 15(3), 54-58. doi: 10.9790/0837-1535458

Kaviraj, S. (2000). Laughter and Subjectivity: The Self-Ironical Tradition in Bengali Literature. Modern Asian Studies, 34(2), 379-406. doi: 10.1017/so026749x00003334

Kehler, A. (2004). Discourse Coherence. In L. R Horn \& G. Ward, The Handbook of Pragmatics. Blackwell Publishing. Retrieved from https://onlinelibrary.wiley.com/doi/pdf/10.1002/9780470756959

Liu, C., \& Huang, N. Analysis of the Characteristics of Children's Poetry - Take Shel Silverstein's Poems for Example. National Hsinchu Girls' Senior High School.

Martin, J. (2019). In D. Tannen, H. Hamilton \& D. Schiffrin, The Handbook of Discourse Analysis (2nd ed.). Wiley Blackwell. 
Montgomery, M., Durant, A., Furniss, T., \& Mills, S. (2013). Ways of reading (3rd ed., pp. 23 - 32, 124 - 157, 199 - 254). London: Routledge.

Reading Comprehension: Theory and Practice. Retrieved from https://shodhganga.inflibnet.ac.in/bitstream/10603/18121/6/o6_chapter\%201.pdf

Shahriar, A., \& Pathan, H. (2012). Coherence and the Role of Cohesion in Coherent Texts. Language In India, 12(5), $373-388$.

Shapiro, L., \& Hudson, J. (1991). Tell me a make-believe story: Coherence and cohesion in young children's picture-elicited narratives. Developmental Psychology, 27(6), 960-974. doi: 10.1037//oo12-1649.27.6.960

Spiro, R. (1980). Schema Theory And Reading Comprehension:New Directions. University of Illinois at Urbana-Champaign.

Tangkiengsirisin, S. Cohesion and Coherence In Text. Language Institute, Thammasat University.

Tartilas, L. (2010). Cohesive Ties in Different Registers (MA). Vilinus Pedagogical University.

van Dijk, T. The Semantics and Pragmatics of Functional Coherence in Discourse, 49 - 65. Retrieved from http://www.discourses.org/OldArticles/The\%20semantics\%20and\%2opragmatics\%200f\%2ofunctional \%20coherence\%2oin\%2odiscourse.pdf

van Dijk, T. (1977). Text and Context - Explorations in the Semantics and Pragmatics of Discourse (pp. 93 114, 167 - 228). New York: Longman.

van Dijk, T. (2006). Discourse, context and cognition. Discourse Studies, 8(1), 159-177. doi: $10.1177 / 1461445606059565$

Wang, Y., \& Guo, M. (2014). A Short Analysis of Discourse Coherence. Journal Of Language Teaching And Research, 5(2), 460 - 465. doi: 10.4304/jltr.5.2.460-465

Witte, S., \& Faigley, L. (1981). Coherence, Cohesion, and Writing Quality. College Composition And Communication, 32(2), 189. doi: 10.2307/356693

Yeh, C. (2004). The Relationship of Cohesion and Coherence: A Contrastive Study of English and Chinese. Journal Of Language And Linguistics, 3(2), 243 - 250. 